\title{
Genetic parameters for health traits using data collected from genomic information nucleus herds
}

\author{
M. Abdelsayed, ${ }^{*}{ }^{1}$ M. Haile-Mariam, ${ }^{*}$ and J. E. Pryce ${ }^{*} \ddagger$ \\ *Agriculture Victoria, AgriBio, Centre for AgriBiosciences, Bundoora, Victoria 3083, Australia \\ †Holstein Australia, Hawthorn East, Victoria 3122, Australia \\ $\ddagger$ School of Applied Systems Biology, La Trobe University, Bundoora, Victoria 3083, Australia
}

\section{ABSTRACT}

As with many other countries, data availability has been a limitation in Australia for developing breeding values for health traits. A genomic information nucleus of approximately 100 herds across the country, selected on the basis of their record keeping, has recently been established in Australia and is known as Ginfo. The objective of this study was to evaluate the feasibility of developing genomic breeding values for health traits using farmer-collected data from Ginfo herds. Having this genotyped population opens up opportunities to develop new genomic breeding values, such as dairy health traits. In these herds, the 4 most recorded groups of health diseases identified were mastitis, reproductive problems, lameness, and metabolic disorders with incidence levels of $16,9,2$, and $1.5 \%$, respectively. Heritability estimates from pedigree and genomic analysis ranged from 0.01 to 0.03 for mastitis, 0.005 to 0.02 for reproductive disorders, 0 to 0.02 for lameness, and 0.00 to 0.06 for metabolic disorders. However, although heritability is low, there is sufficient genetic variation to make genetic progress feasible (coefficient of variation ranging from 3 to 26.3\%). Genetic correlations between health and milk production traits (0.08 to 0.48$)$ and overall type ( -0.00 to 0.57$)$ are unfavorable, but favorable with other economical traits, such as fertility $(0.10$ to 0.51$)$, survival $(-0.16$ to -0.37$)$, and somatic cell count (0.07 to 0.55$)$. For a genomic reference population of 11,458 cows, the reliability of genomic predictions is comparatively low $(<30 \%)$, but is promising for health traits, such as mastitis $(\sim 30 \%)$ and a broader-based all disease trait $(\sim 28 \%)$, when bulls have daughters in the reference population, but not when they only have genomic information (0 to $18 \%$ ). Further improvement of the reliabilities of health breeding values continues to be an important objective. The study has provided a

Received March 31, 2017.

Accepted August 21, 2017.

${ }^{1}$ Corresponding author: mary.abdelsayed@ecodev.vic.gov.au good foundation for future research to develop breeding values for health traits.

Key words: dairy, health trait, genomic, breeding value, reliability

\section{INTRODUCTION}

It is possible to improve dairy farm profitability and animal welfare by selecting for breeding values associated with cow health, leading to less veterinary intervention and cows that are more productive and easier to manage. In the past, dairy production was focused on improving production as the driver of farm profitability. Whereas this led to great genetic gains in milk production, an unfavorable genetic relationship between production and disease resistance became more apparent (Rauw et al., 1998). Many functional traits have negative genetic correlations with production, and these have led to reductions in the fitness and health of dairy cows (Rauw et al., 1998); however, since the 1990s, selection objectives have been broadened to include traits that contribute to the cost of production. Notably, selection objectives in many countries include breeding values for fertility, SCC, longevity, and so on (Miglior et al., 2005; Pryce et al., 2013; Byrne et al., 2016). Traits such as fertility and health generally have lower heritability estimates $(<5 \%)$ in comparison to production traits ( $>30 \%$; Egger-Danner et al., 2015), although sufficient genetic variation exists to make selection feasible for lowly heritable traits.

The era of genomics opens up opportunities to bring rapid progress to the dairy industry for traits that have future effects on the industry, but are too difficult or costly to measure in national populations. There are opportunities to use dedicated reference populations of genotyped females for the prediction and development of genomic breeding values for such traits (e.g., health). Chesnais et al. (2016) concluded that the best approach for cheap and easy-to-measure phenotypes is to use genotyped reference populations of bulls with progeny groups. However, for traits that are expensive 
or difficult to measure, or where data are sparse, a better option is to obtain phenotypes from dedicated reference populations of genotyped cows. This has started in Australia through the establishment of Ginfo, a genomic information nucleus of females with a broad range of recorded phenotypes.

Many countries in Europe and North America already have, or will shortly have, breeding values for health traits estimated using health and antibiotic usage records (Philipsson and Lindhé, 2003; Østerås et al., 2007; Heringstad and Osteras, 2013; Parker Gaddis et al., 2014; Egger-Danner et al., 2015). Use of estimated breeding values from other countries, particularly for health traits, may not be appropriate because of the likely effects of genotype by environment interactions. In fact, there are good reasons to believe that genotype by environment interactions may be even greater for health traits, compared with other traits that are evaluated, because of the differences among countries in their production systems, incidence level, genetic control, and economic importance of disease (Rauw and Gomez-Raya, 2015). Additionally, foreign breeding values are not available for most bulls that are important in Australia, making it necessary to develop them domestically. To date in Australia, 1 preliminary study (using only 2007 and 2008 data), by Haile-Mariam and Goddard (2010), looked at genetic parameter estimates for health traits (udder, reproductive, leg disorders, and all diseases trait). Furthermore, only 2 studies have quantified the incidence of disease in multiple Australian dairy herds (Stevenson 2000; Haile-Mariam and Goddard, 2010).

The overall objective of our study was to provide foundational research for the Australian dairy industry on the feasibility of developing genomic breeding values for health traits using farmer-collected data from genomic information nucleus (Ginfo) herds (genotyped cow reference population). More specifically, the objectives of our study were (1) to assess the quality and quantity of the health data being collected on farm; (2) to estimate the current level of disease incidence; and (3) to estimate genetic parameters for common health traits using pedigree and genomic relationships.

\section{MATERIALS AND METHODS}

\section{Health Data Source}

Health data for our study were extracted from data of about 100 herds that were identified to record good-quality data. These herds were called genomic information nucleus herds (Ginfo). Ginfo was a largescale genotyping project (103 herds and 32,386 cows) to increase the size of the Australian dairy reference population to improve the reliability of genomic breeding values. A total of 487,503 electronic health data records collected by farmers were accessed from 90 herds. After inclusion of herd contemporaries, the total data set consisted of 785,990 records from 168,546 cows that calved from between 1990 and 2015. There were 21,684 cows that were genotyped out of a total 32,386 cows that were part of Ginfo. Out of the 21,684 genotyped cows, 15,632 had at least 1 health record (i.e., from the 168,546 cows with health records).

\section{Disease Categories}

Following the health categories defined by Stevenson (2000) and Haile-Mariam and Goddard (2010), which are comparable Australian studies, we defined the broad categories (1) calving-associated disorders, (2) metabolic diseases, (3) reproductive disorders, (4) mastitis, (5) udder problems, (6) legs (lameness), (7) miscellaneous disorders, (8) management, and (9) abortion. Table 1 contains examples of diseases that each category includes. The all disease category included all categories excluding the management group and was mainly used in the genetic analysis (Table 1). Disease categories were converted into binary traits (i.e., each disease was coded with a 0 or 1 for every cow-lactation record, where 1 corresponds to a cow having a particular disease at any time in a lactation and 0 if it does not have that disease). For the all diseases category, a cow was coded 1 if it had any record of any disease event; otherwise it was coded 0 as healthy. Multiple cases of disease per lactation were used for the calculation of disease incidence, whereas only a single case of disease per lactation was used for the genetic analysis.

\section{Disease Incidence}

Health data from 2000 to 2014 was used in the analysis. The year 2000 coincides with many farms transitioning from paper to electronic recording (Haile-Mariam et al., 2007). Treatment records from 2015 were excluded due to only partial records being available at the time of the study. Health records with calving dates available were used in the analysis. The date of treatments had to be within consecutive calving dates instead of a set number of DIM. According to the study by Stevenson (2000), for each disease category a minimum period between repeat treatments of the same disease needed to elapse for the next occurrence to be considered as a separate disease case. The same restrictions were applied to each of the disease categories, as in the study by Stevenson (2000). Namely, for mastitis and metabolic disorders, a minimum of $7 \mathrm{~d}$; for lameness, reproductive, and miscellaneous disorders a minimum 
of $14 \mathrm{~d}$; for udder disorders, a minimum of $20 \mathrm{~d}$; for abortions a minimum of $100 \mathrm{~d}$; and for calving-related disorders only a single disease event per lactation. To remove potential bias in the analysis, various other data edits were carried out on the health data, such as excluding any treatment records before calving dates, any herd-years with less than 50 cows, and cows less than 18 mo of age at calving in first parity. Using very similar editing rules to Parker Gaddis et al. (2012), herds were also removed if they did not report a health event, as were herds that reported only sick cows, so only data from herds-years with at least 1 reported incidence of any 1 of the health events of interest was considered. After editing, there were 460,732 records from 107,471 cows that calved between 2000 and 2014, including all parity records from 90 herds.

For the calculation of disease incidence, 2 methods of calculation similar to Dohoo et al. (1984) and Stevenson (2000) were used. First, cases per 100 cow-year considered more than 1 occurrence of a disease per lactation, while observing the rule of closely occurring repeats of disease that are likely to be the same disease. That is, a cow may get mastitis many times over her lactation, and these are included in the calculation number of disease events divided by cow-time at risk, where cow time at risk is the number of days between calving date and last observation date or dry off date (count the number of days, sum all together for that disease then divide by 365 to give a cow-year time frame at risk). For the calving-associated disorders, cow-time at risk is calculated as the number of calvings per parity.

Second, cows affected per 100 cow-years is the number of cows with a disease event during a year when the data are coded to presence or absence of disease in a lactation, calculated as the number of cows with disease events divided by the total number of cow-years, both expressed as a percentage. Disease incidence per parity and lactation stage, early $100 \mathrm{~d}$ (first $100 \mathrm{~d}$ of lactation) and late lactation (after $100 \mathrm{~d}$ of lactation), was also calculated.

\section{Pedigree Analysis}

Only 5 major disease traits were evaluated using pedigree and genomic analysis: mastitis, reproductive disorders, lameness, metabolic diseases, and the general all disease trait. The other disease categories (such as udder, abortions, and calving-associated disorders) did not have enough records to provide reliable genetic parameter estimates and are not presented because of high standard errors associated with the estimates.

The pedigree analyses were conducted within breed, and only Holstein and Jersey were considered. For the pedigree analysis, the health data set consisted of 185,295 records from 64,440 Holstein cows $(44,861$ cows had multiple records); for the Jersey cohort, there were 22,114 records from 8,329 cows (5,545 cows had multiple records). The pedigree file was obtained from DataGene (Bundoora, Victoria, Australia). The file was pruned to only include relatives of cows that had phenotypic records, and individuals with phenotypes were removed where their sires had less than 5 daughters (Haile-Mariam and Goddard, 2010). After editing, the Holstein pedigree file contained 78,170 animals from 5,368 sires and 48,596 dams, and the Jersey pedigree file contained 10,671 animals from 901 sires and 7,009 dams.

The health data were analyzed using a linear mixed animal model in ASReml (Gilmour et al., 2015). In matrix notation, the model was

$$
\mathbf{y}=\mathbf{X b}+\mathbf{Z a}+\mathbf{W c}+\mathbf{e}
$$

Table 1. Dairy health categories and the associated diseases included within each category and the abbreviated health codes

\begin{tabular}{|c|c|c|}
\hline Disease category & Abbreviation & Diseases included \\
\hline Metabolic diseases & METAB & Milk fever, grass tetany, ketosis \\
\hline Mastitis & MAST & Clinical and subclinical \\
\hline Udder & UDD & Teat disorder, udder disorders, udder edema, blind quarters, abscess on udder, 3 teater \\
\hline Legs (lameness) & LAME & $\begin{array}{l}\text { Foot disorders, leg disorders, other musculoskeletal disorders (any condition causing } \\
\text { lameness not associated with foot problems; e.g., spinal) }\end{array}$ \\
\hline Management & MANAG & Dry cow treatment, drenches, nutritional supplements, hormonal treatments \\
\hline Abortion & ABOR & Abortions that occurred after $100 \mathrm{~d}$ \\
\hline All disease ${ }^{1}$ & ALLDIS & Grouped all diseases excluding management \\
\hline
\end{tabular}

${ }^{1}$ Used in the genetic analysis. 
where $\mathbf{y}=$ vector of observable health traits $(0$ for healthy cows or 1 for cows with a disease); $\mathbf{b}=$ vector of fixed effects of herd of calving, year of calving, season [which is month of calving divided into 2 groups: $1=$ January to July (autumn calving) and $2=\mathrm{Au}-$ gust to December (spring calving)], all combined into a contemporary group (HYS), parity categorized into 4 classes (with the fourth class grouping any parity greater than 4 together), effect of month of calving (1 to 12), age at calving (from 18 to 220 mo fitted as a covariate and second order polynomial); $\mathbf{a}=$ vector of random animal polygenic term incorporating pedigree structure, or for the genomic analysis incorporating the genomic relationship matrix; $\mathbf{c}=$ vector of random permanent environmental effect of the cow, to account for repeated lactations; $\mathbf{e}=$ vector of random residual effect specific to each trait; and $\mathbf{X}, \mathbf{Z}$, and $\mathbf{W}=$ incidence matrices for $\mathbf{b}$, $\mathbf{a}$, and $\mathbf{c}$, respectively. The parity effect was not fitted when analyzing first parity.

For the random effects, we assumed the (co) variance structure

$$
\operatorname{var}\left[\begin{array}{l}
\mathbf{a} \\
\mathbf{c} \\
\mathbf{e}
\end{array}\right]=\left(\begin{array}{ccc}
\mathbf{A} \sigma_{\mathbf{a}}^{2} & 0 & 0 \\
0 & \mathbf{I} \sigma_{\mathbf{c}}^{2} & 0 \\
0 & 0 & \mathbf{I} \sigma_{\mathbf{e}}^{2}
\end{array}\right)
$$

where $\mathbf{a}$ is the vector of animal effects, $\mathbf{c}$ is the vector of cow effects, and $\mathbf{e}$ the vector of residual error. All random effects have a mean of zero; $\mathbf{A} \sigma_{\mathrm{a}}^{2}, \mathbf{I} \sigma_{\mathbf{c}}^{2}$, and $\mathbf{I} \sigma_{\mathbf{e}}^{2}$ correspond to the animal, permanent environmental cow, and residual variance, respectively. A represents the additive or genomic relationship of animals and their ancestors and $\mathbf{I}$ is the identity matrix.

Univariate models were fitted to the health data to estimate variance components for the calculation of heritability and repeatability for each of the 5 disease traits. The additive genetic variance from each of the univariate trait models was used to calculate the coefficient of genetic variation (CV) using the formula for binary traits

$$
\mathrm{CV}(\%)=100 \times \frac{\sigma_{a}^{2}}{\bar{X}}
$$

where $\sigma_{a}^{2}$ is the additive genetic variance and $\bar{X}$ trait average is calculated due to the binary nature of the traits as $\sqrt{\left[\left(X_{\text {mean }}-X_{\min }\right)\left(X_{\max }-X_{\text {mean }}\right)\right]}$, with the upper and lower boundaries, minimum $(\min )=0$ and maximum $(\max )=1$ and $\mathrm{X}_{\text {mean }}=$ trait mean (Burdon, 2008).
Bivariate linear animal mixed models (same as the univariate model) were fitted using pedigree and genomic data to obtain variance and covariance estimates for the calculation of genetic and phenotypic correlations between disease traits (mastitis, lameness, reproductive disorders, metabolic diseases, and all diseases) for first- and all-parity records.

Bivariate models were also used to calculate genetic correlations between health traits and other economically important traits. For convenience and consistency, precorrected phenotypes (trait deviations) for calving interval (fertility), survival, SCC, BCS, and type traits obtained from DataGene were used. Trait deviations (TD) are measures of the performance of cows adjusted for environmental factors (herd-year-season contemporary groups, stage of lactation, and age at calving), using first-parity records for type traits. However, for other traits, such as fertility, SCC, and survival, TD were calculated using the records available for each cow after adjusting for repeated records as well. For correlations between disease traits and production traits, 305-d lactation milk, fat, and protein yields were used.

Only genetic correlations for Holstein results will be reported, as the standard errors estimated using Jersey data were large. A summary of the number of records used in the pedigree (genetic) analysis for each health trait is reported in Table 2 for each breed.

\section{Genomic Analysis}

Analysis Method. For the genomic analysis, the same mixed models were fitted as for the pedigree analysis using ASReml (Gilmour et al., 2015), but the pedigree relationship matrix was replaced with a genomic relationship matrix (GRM). To construct the GRM, the genotypes of the 15,632 cows with health records and 2,984 bulls with daughter health records were obtained from DataGene. The GRM for cows and bulls in each breed was constructed separately, following Yang et al. (2010), so that the analysis was within breed (which is consistent with the pedigree analysis). A separate data set using only the genotyped animals with health records was used for the genomic analysis and divided into a reference and validation data set.

The reference data set consisted of 11,458 genotyped Holstein cows (out of the total 15,632 genotyped Ginfo cows), with 1,416 sires; of those, 948 sires were genotyped. In the data set were 1,601 genotyped Jersey cows, with 274 sires; of those, only 188 sires were genotyped. The genotyped sires were included in the calculation of the genomic relationship matrix to obtain direct genetic values (DGV). The genotyped sires were included in the cow health file but did not have any 
Table 2. Summary of the number of healthy (0) and diseased cases (1) in the data sets used in the pedigree (Ped) and genomic (Geno) analysis for each health trait for Holsteins and Jerseys divided into the records used for 1st and all parity analysis

\begin{tabular}{|c|c|c|c|c|c|c|c|c|}
\hline \multirow[b]{2}{*}{ Disease $^{1}$} & \multicolumn{2}{|c|}{ 1st parity Ped } & \multicolumn{2}{|c|}{ All parity Ped } & \multicolumn{2}{|c|}{ 1st parity Geno } & \multicolumn{2}{|c|}{ All parity Geno } \\
\hline & 1 & 0 & 1 & 0 & 1 & 0 & 1 & 0 \\
\hline \multicolumn{9}{|l|}{ Holsteins } \\
\hline MAST & 3,599 & 46,040 & 20,288 & 165,007 & 901 & 9,930 & 3,735 & 29,265 \\
\hline REPRO & 3,732 & 45,707 & 14,256 & 171,039 & 787 & 10,044 & 2,498 & 30,502 \\
\hline LAME & 955 & 48,484 & 3,197 & 182,098 & 93 & 10,738 & 248 & 32,752 \\
\hline METAB & 328 & 49,111 & 2,080 & 183,215 & 73 & 10,758 & 241 & 32,759 \\
\hline ALLDIS & 7,788 & 41,651 & 34,461 & 150,834 & 1,780 & 9,051 & 6,085 & 26,915 \\
\hline \multicolumn{9}{|l|}{ Jerseys } \\
\hline MAST & 384 & 5,877 & 1,409 & 20,705 & 93 & 1,392 & 314 & 4,824 \\
\hline REPRO & 141 & 6,120 & 456 & 21,658 & 48 & 1,437 & 161 & 4,977 \\
\hline LAME & 112 & 6,149 & 326 & 21,788 & 30 & 1,455 & 89 & 5,049 \\
\hline METAB & 8 & 6,253 & 409 & 21,705 & 2 & 1,483 & 90 & 5,048 \\
\hline ALLDIS & 652 & 5,609 & 2,478 & 19,636 & 170 & 1,315 & 603 & 4,535 \\
\hline
\end{tabular}

${ }^{1}$ Refer to Table 1 for trait definitions.

phenotypes (daughter trait deviations) in the reference data set, so they were included with missing values. A summary of the number of records used in the genomic analysis for each health trait is also reported in Table 2 for each breed. The validation data set consisted of 494 genotyped bulls that had 6,989 ungenotyped daughters with 22,276 records. Sires with less than 5 daughter records were not used for cross-validation because the accuracy of individual cow records or of sires with less than 5 daughters is very low.

Bivariate analyses using the genomic data set were attempted, but correlations are not reported because the models either did not converge or produced estimates with large standard errors. Therefore, genetic correlations from only the pedigree analyses are reported.

Reliability of Genomic Prediction. Two methods were used to estimate the reliability of genomic prediction. First, theoretical (expected) reliability $(\mathbf{R})$ was calculated as

$$
\mathrm{R}=1-\frac{\mathrm{PEV}}{\sigma_{g}^{2}}
$$

where prediction error variance $(\mathrm{PEV})=$ squared standard error of the DGV for each animal in the data set, and $\sigma_{g}^{2}=$ additive genetic (genomic) variance obtained from ASReml (Gilmour et al., 2015).

Second, empirical (observed) reliability using crossvalidation (Rel) was performed by predicting direct genomic breeding value for the 494 genotyped bulls that had daughters with health records and that were not genotyped (so not included in the reference set). This was used to test how well the model predicts phenotypes (health traits) when only genotypes are provided. Reliability (Rel) was then estimated as a simple Pearson's squared correlation between the DGV and the daughter trait deviations (DTD) for each bull. A DTD is the sire equivalent of a trait deviation (i.e., the performance of daughters corrected for fixed effects). The reliability was then adjusted by dividing by the effective heritability and average number of effective daughters $\left(\mathrm{n}_{\mathrm{dtrs}}\right.$; Haile-Mariam et al., 2013), calculated as

$$
\text { Rel }=\frac{r(D G V, D T D)^{2}}{h^{2} \times n_{d t r s}} .
$$

To calculate DTD for the genotyped bulls, a fixed effect-only model was fitted to the full Holstein health data file to obtain corrected phenotypes. Trait deviations (TD) were first calculated for the ungenotyped daughters, which were progeny of genotyped bulls, as

$$
\mathrm{TD}=\frac{\sum \text { residuals }}{\text { No. of lactations }} .
$$

The DTD were then calculated for each genotyped sire using his daughters TD as

$$
\mathrm{DTD}=\frac{\sum \mathrm{TD}}{\text { No. of daughters }} .
$$

For comparison, the expected reliability was also estimated for the validation bulls.

\section{RESULTS}

\section{Disease Incidence}

Disease incidence can be reported by considering either repeat occurrences of disease per time period 
Table 3. Incidences for each of the disease categories using records from 2000 to 2014 using 2 methods of calculating incidence: cases per 100 cow-years (full data set) and cows affected per 100 cow-years for all breeds (Holstein, Jerseys, and crossbreeds), Holsteins, and Jerseys ${ }^{1}$

\begin{tabular}{|c|c|c|c|c|c|c|c|c|c|}
\hline Item & MAST & LAME & REPRO & META & UDD & CALV & ABOR & MISC & ALLDIS \\
\hline \multicolumn{10}{|l|}{ Cases per 100 cow-years } \\
\hline No. of disease records & 43,887 & 5,232 & 23.849 & 3.977 & 886 & 61 & 1,029 & Full data set & 105.092 \\
\hline \multicolumn{10}{|c|}{ Cows affected per 100 cow-years } \\
\hline \multicolumn{10}{|l|}{ All breeds } \\
\hline No. of disease records & 31,672 & 4,694 & 18,873 & 3,738 & 866 & 61 & 1,019 & 13,498 & 74,421 \\
\hline No. of disease records & 22,409 & 3,492 & 15,147 & 2,267 & 518 & 47 & 705 & 9,534 & 54,119 \\
\hline Incidences & 9.2 & 1.7 & 6.2 & 0.92 & 0.21 & 0.02 & 0.29 & 4.0 & 22.4 \\
\hline \multicolumn{10}{|l|}{ Jersey } \\
\hline No. of disease records & 1,585 & 369 & 509 & 468 & 94 & 4 & 61 & 1,110 & 4,200 \\
\hline Incidences & 5.7 & 1.3 & 1.8 & 1.7 & 0.34 & 0.01 & 0.24 & 4.0 & 15.1 \\
\hline
\end{tabular}

${ }^{1}$ Refer to Table 1 for trait definitions.

(number of cases) or by considering if there was at least 1 occurrence of a disease per time period. The 2 diseases that had the highest number of either cases or cows affected were mastitis and reproductive disorders, followed by lameness, metabolic diseases, udder, abortion, and calving-associated disorders (Table 3). Overall in this data set, we noted about 40 cases of disease being recorded per 100 cows per year.

Incidences by breeds (cows affected per 100) were similar between the all breeds and Holstein data sets. This is expected because the all-breeds data set was dominated by Holsteins (67\% Holsteins, 9\% Jerseys, and $23 \%$ crossbreds). Jerseys had lower incidence for all diseases except metabolic, with the largest difference between breeds for mastitis (9.2 vs 5.7\%; Table 3).

In general, incidences (cases) increased with parity to a larger extent for mastitis and metabolic diseases (Table 4). Mastitis had the highest incidence in later parities followed by reproductive disorders. Most cases of disease occurred in the first $100 \mathrm{~d}$ of lactation. For example, for mastitis, reproductive, and miscellaneous disorders, 70,79 , and $67 \%$ of incidences occurred in the first $100 \mathrm{~d}$ of lactation, respectively.

\section{Pedigree Analysis}

Only the 5 major disease traits were included in the pedigree analysis: mastitis, reproductive disorders, lameness, metabolic diseases, and the all disease trait. The other disease categories, such as udder, abortions, and calving-associated disorders, had very low incidences $(0.28,0.96$, and $0.02 \%$, respectively) and insufficient records to provide reliable genetic parameter estimates. These traits could be analyzed in the future as more health data gets collated.

Heritability. Heritabilities for health traits were low for both breeds, and first- and all-parity analyses (Table 5), ranging from 0.00 to 0.02 . Mastitis and all diseases were the 2 traits with the highest heritability estimates for Holsteins using pedigree analysis. Health traits were generally more heritable when using all parity records for Holsteins when using the pedigree analysis, except for lameness, which was more heritable in first parity. For Jerseys, the heritability of health traits in the first was fairly similar to that in all parity; however, heritability estimates for metabolic diseases for Jerseys in first parity were excluded, as they were only based on

Table 4. Overall disease incidence rate (cases per 100 cow-years) and in parentheses is the rate of cows affected (per 100 cow-years) across parities for each of the disease categories, mastitis (MAST), lameness (LAME), reproductive (REPRO), metabolic (METAB), udder (UDD), and miscellaneous disorders (MISC) using all breed records

\begin{tabular}{|c|c|c|c|c|c|c|}
\hline Parity & MAST & LAME & REPRO & METAB & UDD & MISC \\
\hline 1 & $9.4(6.4)$ & $2.0(1.4)$ & $7.9(5.0)$ & $0.62(0.5)$ & $0.23(0.17)$ & $9.1(3.8)$ \\
\hline 2 & $11.7(7.1)$ & $1.5(1.1)$ & $8.8(5.4)$ & $0.83(0.6)$ & $0.23(0.18)$ & $7.9(3.3)$ \\
\hline 3 to 6 & $20.8(10.5)$ & $2.0(1.3)$ & $9.0(5.3)$ & $2.0(1.3)$ & $0.37(0.27)$ & $10.2(3.9)$ \\
\hline $7+$ & $32.7(12.5)$ & $3.1(1.7)$ & $12.0(6.0)$ & $4.4(2.5)$ & $0.84(0.49)$ & $15.2(4.4)$ \\
\hline
\end{tabular}


Table 5. Heritability $( \pm \mathrm{SE})$ estimates of disease traits from pedigree (Ped) and genomic (Geno) analysis for Holsteins and Jerseys in 1st and all parity

\begin{tabular}{|c|c|c|c|c|c|c|}
\hline Item $^{1}$ & \multicolumn{2}{|c|}{ 1st parity } & \multicolumn{2}{|c|}{ All parity } & $\mathrm{CV} \% \mathrm{Ped}^{2}$ & CV\% Geno 2 \\
\hline MAST & $0.01 \pm 0.004$ & $0.02 \pm 0.008$ & $0.02 \pm 0.002$ & $0.03 \pm 0.006$ & 12.1 & 14.4 \\
\hline REPRO & $0.005 \pm 0.003$ & $0.02 \pm 0.008$ & $0.01 \pm 0.002$ & $0.01 \pm 0.001$ & 7.2 & 6.0 \\
\hline LAME & $0.02 \pm 0.004$ & $0.00 \pm 0.000$ & $0.007 \pm 0.001$ & $0.00 \pm 0.000$ & 7.6 & 0.05 \\
\hline METAB & $0.002 \pm 0.002$ & $0.003 \pm 0.005$ & $0.007 \pm 0.001$ & $0.002 \pm 0.005$ & 9.4 & 3.1 \\
\hline MAST & $0.02 \pm 0.01$ & $0.10 \pm 0.05$ & $0.01 \pm 0.005$ & $0.03 \pm 0.01$ & 8.8 & 16.3 \\
\hline REPRO & $0.01 \pm 0.01$ & $0.005 \pm 0.03$ & $0.005 \pm 0.004$ & $0.01 \pm 0.01$ & 7.0 & 11.3 \\
\hline LAME & $0.006 \pm 0.01$ & $0.00 \pm 0.00$ & $0.003 \pm 0.003$ & $0.00 \pm 0.00$ & 0 & 0.04 \\
\hline METAB & $\mathrm{NA}^{3}$ & NA & $0.007 \pm 0.004$ & $0.06 \pm 0.02$ & 7.3 & 26.3 \\
\hline ALLDIS & $0.02 \pm 0.01$ & $0.00 \pm 0.000$ & $0.01 \pm 0.005$ & $0.02 \pm 0.01$ & 9.4 & 12.2 \\
\hline
\end{tabular}

${ }^{1}$ Refer to Table 1 for trait definitions.

${ }^{2}$ The CV for all parity data under the pedigree (Ped) and genomic (Geno) analyses.

${ }^{3} \mathrm{NA}=$ not available.

8 recorded cases (Table 2), which would be unreliable to report. Repeatability estimates did not differ greatly from the heritability estimates, ranging from 0.02 to 0.06 for health traits for both breeds. The CV for each of the health traits using all-parity data were generally higher than the heritability estimates for both breeds and under pedigree and genomic analysis (Table 5), indicating substantial genetic variation among health traits. The CV for each of the traits were generally higher in the pedigree analysis for Holsteins, except for mastitis and the all disease trait, where the CV was higher in the genomic analysis. Jerseys had lower CV than Holsteins in the pedigree analysis especially lameness $(0 \%)$, but Jerseys tended to have higher CV in the genomic analysis for all health traits, with metabolic diseases being the highest, which is associated with the higher heritability estimate.

Correlations Between Health Traits. Genetic and phenotypic correlations between health traits for Holsteins using all parities are reported in Table 6. Genetic correlations between disease traits were higher in first parity (not tabulated) than all parities, although repeated records gave better estimates than first-parity estimates, which had higher standard errors. As expect- ed, the all disease trait had moderate to high positive genetic and phenotypic correlations with other diseases, indicating that 1 trait could be used for indirect selection to improve other health traits. Genetic correlations were low between metabolic disorders and lameness. Generally, phenotypic correlations between diseases were lower than genetic correlations for both first- and all-parity analyses.

Genetic Correlations Between Health Traits and other Economically Important Traits. Genetic correlations between disease traits and economically important traits and type traits are reported in Table 7. The metabolic health category was excluded due to parameter estimation convergence failure, as a result of the limited number of records available.

Generally, relationships between production traits and diseases were unfavorable, as expected. Favorable relationships were evident between mastitis and SCC, between health traits (mastitis, lameness, reproductive disorders, and all diseases) and BCS, and between health and survival and fertility (calving interval) traits. Unfavorable genetic correlations were found between overall type and diseases (mastitis, reproductive disorders, and all diseases), even after adjusting overall type for milk

Table 6. Genetic (above diagonal) and phenotypic correlations (below diagonal) \pm SE between health traits for Holsteins in all parity using linear animal model based on pedigree information ${ }^{1}$

\begin{tabular}{lcccrc}
\hline Item & MAST & REPRO & LAME & \multicolumn{1}{c}{ METAB } & \multicolumn{1}{c}{ ALLDIS } \\
\hline MAST & & $0.18 \pm 0.09$ & $0.19 \pm 0.10$ & $-0.03 \pm 0.10$ & $0.86 \pm 0.03$ \\
REPRO & $0.04 \pm 0.002$ & & $0.06 \pm 0.12$ & $0.11 \pm 0.12$ & $0.55 \pm 0.07$ \\
LAME & $0.01 \pm 0.002$ & $0.03 \pm 0.002$ & & $-0.07 \pm 0.13$ & $0.34 \pm 0.09$ \\
METAB & $0.02 \pm 0.002$ & $0.03 \pm 0.002$ & $0.02 \pm 0.002$ & & $0.16 \pm 0.10$ \\
ALLDIS & $0.66 \pm 0.001$ & $0.42 \pm 0.002$ & $0.21 \pm 0.002$ & $0.10 \pm 0.002$ & \\
\hline
\end{tabular}

${ }^{1}$ Refer to Table 1 for trait definitions. 
Table 7. Genetic correlations $\pm \mathrm{SE}$ of health traits, mastitis (MAST), reproductive disorders (REPRO), lameness (LAME), and all diseases (ALLDIS) of 1st parity with other important traits to dairy producers [i.e., trait deviations (TD) of Holstein breed using the linear animal model based on pedigree information] and the number of records (n) for each trait

\begin{tabular}{|c|c|c|c|c|c|}
\hline Trait $^{1}$ & $\mathrm{n}$ & MAST & REPRO & LAME & ALLDIS \\
\hline MY & 42,942 & $0.48 \pm 0.10$ & $0.37 \pm 0.19$ & $0.18 \pm 0.09$ & $0.33 \pm 0.10$ \\
\hline FY & 42,942 & $0.08 \pm 0.12$ & $0.25 \pm 0.19$ & $0.12 \pm 0.10$ & $0.16 \pm 0.11$ \\
\hline PY & 42,942 & $0.44 \pm 0.10$ & $0.28 \pm 0.21$ & $0.13 \pm 0.10$ & $0.28 \pm 0.11$ \\
\hline Fertility & 38,253 & $0.50 \pm 0.14$ & $0.35 \pm 0.19$ & $0.10 \pm 0.12$ & $0.51 \pm 0.13$ \\
\hline SCC & 43,126 & $0.55 \pm 0.11$ & $0.14 \pm 0.14$ & $0.07 \pm 0.09$ & $0.38 \pm 0.10$ \\
\hline Otype & 13,561 & $0.34 \pm 0.15$ & $0.57 \pm 0.17$ & $-0.002 \pm 0.18$ & $0.56 \pm 0.16$ \\
\hline Otmy & 13,561 & $0.28 \pm 0.17$ & $0.52 \pm 0.22$ & $-0.04 \pm 0.19$ & $0.45 \pm 0.19$ \\
\hline $\mathrm{BCS}$ & 13,009 & $-0.10 \pm 0.18$ & $-0.14 \pm 0.25$ & $0.14 \pm 0.18$ & $-0.24 \pm 0.19$ \\
\hline Survival & 43,765 & $-0.35 \pm 0.16$ & $-0.13 \pm 0.21$ & $-0.16 \pm 0.14$ & $-0.37 \pm 0.14$ \\
\hline MSpeed & 23,885 & $-0.02 \pm 0.14$ & $0.03 \pm 0.40$ & $-0.14 \pm 0.15$ & $-0.04 \pm 0.14$ \\
\hline Temp & 23,885 & $-0.08 \pm 0.14$ & $0.46 \pm 0.73$ & $-0.19 \pm 0.15$ & $0.16 \pm 0.14$ \\
\hline Like & 23,885 & $-0.12 \pm 0.15$ & $0.18 \pm 0.46$ & $-0.27 \pm 0.15$ & $-0.21 \pm 0.14$ \\
\hline Stat & 13,561 & $0.29 \pm 0.14$ & $0.50 \pm 0.21$ & $-0.10 \pm 0.16$ & $0.38 \pm 0.18$ \\
\hline UdTex & 13,561 & $0.02 \pm 0.18$ & $0.49 \pm 0.23$ & $0.02 \pm 0.20$ & $0.36 \pm 0.21$ \\
\hline Bone & 13,561 & $-0.07 \pm 0.15$ & $0.28 \pm 0.20$ & $-0.01 \pm 0.17$ & $0.16 \pm 0.17$ \\
\hline Angul & 13,561 & $0.40 \pm 0.15$ & $0.49 \pm 0.21$ & $0.25 \pm 0.17$ & $0.79 \pm 0.16$ \\
\hline MuzW & 13,561 & $-0.006 \pm 0.15$ & $0.12 \pm 0.20$ & $-0.04 \pm 0.17$ & $-0.10 \pm 0.18$ \\
\hline ChestW & 13,561 & $0.05 \pm 0.16$ & $0.19 \pm 0.22$ & $0.07 \pm 0.18$ & $0.02 \pm 0.19$ \\
\hline PinW & 13,560 & $0.13 \pm 0.14$ & $0.27 \pm 0.17$ & $0.16 \pm 0.16$ & $0.27 \pm 0.16$ \\
\hline PinSet & 13,560 & $-0.008 \pm 0.14$ & $-0.37 \pm 0.19$ & $-0.35 \pm 0.16$ & $-0.42 \pm 0.16$ \\
\hline RSet & 13,560 & $0.21 \pm 0.18$ & $-0.14 \pm 0.24$ & $-0.36 \pm 0.21$ & $0.09 \pm 0.21$ \\
\hline ForeA & 13,560 & $0.14 \pm 0.16$ & $0.36 \pm 0.20$ & $-0.17 \pm 0.18$ & $0.38 \pm 0.17$ \\
\hline RearAH & 13,560 & $0.26 \pm 0.14$ & $-0.18 \pm 0.21$ & $0.10 \pm 0.17$ & $0.08 \pm 0.17$ \\
\hline RearAW & 13,560 & $0.30 \pm 0.15$ & $0.29 \pm 0.20$ & $0.20 \pm 0.17$ & $0.44 \pm 0.17$ \\
\hline CentL & 13,560 & $0.10 \pm 0.17$ & $0.37 \pm 0.24$ & $0.28 \pm 0.17$ & $0.31 \pm 0.18$ \\
\hline TeatPF & 13,560 & $-0.24 \pm 0.13$ & $0.32 \pm 0.19$ & $0.05 \pm 0.16$ & $0.15 \pm 0.17$ \\
\hline Mamm & 15,533 & $0.21 \pm 0.16$ & $0.38 \pm 0.20$ & $-0.12 \pm 0.18$ & $0.28 \pm 0.18$ \\
\hline BodyD & 13,560 & $0.30 \pm 0.13$ & $0.48 \pm 0.18$ & $0.14 \pm 0.16$ & $0.59 \pm 0.16$ \\
\hline FootA & 13,560 & $-0.06 \pm 0.15$ & $0.14 \pm 0.20$ & $0.19 \pm 0.18$ & $-0.11 \pm 0.18$ \\
\hline UdDep & 13,560 & $-0.26 \pm 0.14$ & $0.01 \pm 0.18$ & $-0.06 \pm 0.16$ & $-0.33 \pm 0.17$ \\
\hline TeatL & 13,560 & $0.08 \pm 0.14$ & $-0.10 \pm 0.19$ & $0.03 \pm 0.16$ & $-0.09 \pm 0.17$ \\
\hline Loin & 12,526 & $0.41 \pm 0.15$ & $0.32 \pm 0.25$ & $0.24 \pm 0.16$ & $0.36 \pm 0.18$ \\
\hline RLeg & 13,289 & $0.32 \pm 0.19$ & $0.41 \pm 0.21$ & $0.03 \pm 0.19$ & $0.61 \pm 0.19$ \\
\hline TeatPR & 12,523 & $0.10 \pm 0.15$ & $0.36 \pm 0.28$ & $0.14 \pm 0.15$ & $0.33 \pm 0.18$ \\
\hline
\end{tabular}

${ }^{1}$ Trait names in order as they appear in table, 305-d milk yield (MY), 305-d fat yield (FY), 305-d protein yield (PY), calving interval (fertility), overall type (Otype), overall type adjusted for milk yield (Otmy), milking speed (MSpeed), temperament (Temp), likability (Like), stature (Stat), udder texture (UdTex), bone density (Bone), angularity (Angul), muzzle width (MuzW), chest width (ChestW), pin width (PinW), pin set (PinSet), rear set (RSet), fore attachement (ForeA), rear attachment height (RearAH), rear attachment width (RearAW), center ligament (CentL), teat placement front (TeatPF), mammary system (Mamm), body depth (BodyD), foot angle (FootA), udder depth (UdDep), teat length (TeatL), loin strength (Loin), rear leg rear view (Rleg), and teat placement rear (TeatPR).

yield. Angularity was moderately to highly positively correlated with disease traits. Udder traits, mammary system, and udder depth have expected relationships with mastitis (i.e., better udder conformation is associated with lower incidences of the disease).

\section{Genomic Analysis}

Genomic estimates of heritability were generally slightly higher than the pedigree analysis for both firstand all-parity analyses for both breeds (Table 5). As with the pedigree analysis, mastitis and all diseases were also the 2 traits with the highest heritability estimates for Holsteins. Heritabilities for Jerseys were highest for mastitis in first parity and metabolic diseases in all par- ity when using genomic relationships, but had higher standard errors (because of a smaller data set). Similar to the pedigree analysis, metabolic diseases in first parity in Jerseys were based on only 2 recorded cases; accordingly, estimates were not included. Whereas the all disease trait in first parity and lameness in first and all parity had estimates of zero heritability.

Only the results of Holsteins are reported due to very large standard errors associated with Jersey estimates. Table 8 shows the average expected reliabilities for each of the health traits for Holstein genotyped cows and genotyped bulls with daughter records in the reference set. Table 9 includes reliability measured as the squared correlation between DGV and DTD, and reliability from predicted error variance for the cross 
Table 8. Average reliabilities (R) of breeding values estimated from the genomics model for the reference population of pure Holstein cows and bulls with daughters in the reference set for each health trait ${ }^{1}$

\begin{tabular}{lccc}
\hline Trait $^{2}$ & All bulls & Bulls $>5$ daughters & Cows \\
\hline MAST & 0.27 & 0.33 & 0.23 \\
REPRO & 0.12 & 0.15 & 0.09 \\
ALLDIS & 0.25 & 0.31 & 0.20 \\
\hline
\end{tabular}

${ }^{1}$ All bulls genotyped $(\mathrm{n}=948)$, Bulls $>5$ daughters $(\mathrm{n}=308)$, cows genotyped $(\mathrm{n}=11,458)$.

${ }^{2}$ Refer to Table 1 for trait definitions.

validation genotyped bulls with no daughters in the reference population (ungenotyped daughters). The predicted error variance (Table 8) and cross validation (Table 9) methods produced similar estimates of reliability. The reliabilities were highest for mastitis and all disease category, followed by reproductive disorders. Results for lameness and metabolic diseases are not included because the heritability was zero, and therefore reliabilities were effectively zero (Table 5) due to both traits having a small number of records in comparison to the other health traits.

Reliabilities were generally low for the health traits, but for bulls with daughters in the reference set (Table 8 ) the reliabilities were higher and more promising than the cross-validation bulls with only genomic information (no daughters in the reference population; Table 9 ). Bulls with greater than 5 daughters had the highest reliability for all health traits when compared with all bulls and cows.

\section{DISCUSSION}

Our study is the first attempt to develop genomic breeding values for health traits in Australia. This was facilitated by the availability of data from a genomic reference population (Ginfo), where health data were available on a population selected for completeness of phenotypes of importance to the Australian dairy industry.

Generally, incidences from this data set are less than those previously reported in other countries, especially for lameness, metabolic disorders, and reproductive disorders (Clarkson et al., 1996; Zwald et al., 2004a; Espejo et al., 2006; Østerås et al., 2007; Parker Gaddis et al., 2012). Previous studies generally had larger data sets, especially studies from some European countries, where they have centralized databases established for national routine health recording; however, the incidences presented here are within similar ranges of the 2 previous Australian studies (Stevenson, 2000; Haile-Mariam and Goddard, 2010). Mastitis had the highest incidence and the largest percentage of cows being treated for
Table 9. Reliability (Rel) of genomic estimated breeding values for the cross-validation bulls for each of the health traits ${ }^{1}$

\begin{tabular}{lll}
\hline Trait $^{2}$ & Rel & $\mathrm{R}$ \\
\hline MAST & 0.04 & 0.18 \\
REPRO & 0.004 & 0.05 \\
ALLDIS & 0.12 & 0.16 \\
\hline
\end{tabular}

${ }^{1}$ For comparison the average reliability $(\mathrm{R})$ calculated using prediction error variance for the cross-validation bulls is presented.

${ }^{2}$ Refer to Table 1 for trait definitions.

mastitis. This was expected, as udder health is a major problem in dairy cows in Australia (Haile-Mariam and Goddard, 2010) and in many other countries (Hogeveen et al., 2011; Schroeder, 2012).

Farmers have milk company compliance agreements that require them to record treatments administered. This may suggest that only severe cases that require treatment were being recorded in most cases. Whereas the data set may underestimate the incidence of diseases (severe cases only being reported), from a breeding perspective this is an acceptable outcome, as selection can then be against the most severe and costly cases of disease. Miglior et al. (2013) reported that Pearson correlations greater than 0.95 were found between sire breeding values calculated using data from different validation scenarios of differing incidences (Miglior et al., 2013), suggesting that under-reporting of data does not appear to affect estimation of breeding values to a large degree.

Incidences of disease increased with parity agrees with other studies (Stevenson 2000; Zwald et al., 2004a). Similarly, the fact that incidences of disease were higher in the first $100 \mathrm{~d}$ of lactation also agrees with other studies (Stevenson 2000; Zwald et al., 2004a; Haile-Mariam and Goddard, 2010). This is expected, as health issues that were seen in cows were usually associated with early and peak lactation, which is the period between the first 30 and $100 \mathrm{~d}$ (Erb et al., 1984).

Threshold models are usually preferred for analyzing binary traits (Gianola, 1982; Moreno et al., 1997); however, the limitation with threshold models is that results need to be transformed from a underlying liability scale to a continuous scale for ease of interpretation. For this reason, a linear model can be used to get reasonably good approximations (and may be easier to interpret). Linear mixed models also have the advantage of being more flexible in fitting multitrait models and may be more appropriate in terms of reliability (Jamrozik et al., 2005; Loker et al., 2012). A study in Canada used both a threshold and a linear model to analyze their health data and reported that using the threshold model did not improve the goodness of fit when compared with the linear model (Neuenschwander, 2010). 
Although heritability estimates were generally higher using threshold models (Kadarmideen et al., 2000), using a threshold, or linear, model has little effect on the ranking of animals on EBV (Ramirez-Valverde et al., 2001; Jamrozik et al., 2005). A study by Negussie et al., (2008) reported similar estimates of genetic correlations when they performed a bivariate analysis between clinical mastitis and continuous traits using both a threshold and a linear model. As a result, genetic parameters estimated in our study using the linear animal model are still applicable.

Heritability estimated for the current study for Holsteins and Jerseys were low, but still within expected ranges reported in the literature (Sander-Nielsen et al., 1999; Kadarmideen and Pryce, 2001; Dechow et al., 2004; Zwald et al., 2004a; Haile-Mariam and Goddard, 2010; Neuenschwander et al., 2012) for first and all parities. However, caution should be taken with the estimates for Jersey, because they are associated with large standard errors.

Heritability estimates of binary traits from linear models are frequency dependent. Accordingly, the lower heritability seen in our study and more so in first parity for Holsteins may be associated with the lower number of records in first parity compared with all parity. For our study, mastitis was put in a category on its own rather than being combined within the udder health category, which may reflect the slightly lower heritability estimate of this study compared with 0.035 in the study by Haile-Mariam and Goddard (2010). Heritability estimates for lameness and all diseases were also fairly similar to the leg (0.013) and all diseases (0.016) traits to that Australian study (Haile-Mariam and Goddard, 2010). For first- and all-parity analyses, the heritability for the all disease trait did not change.

Lameness was more heritable in first parity compared with later parities using the pedigree analysis. Thus, selection on lameness would be more effective using first-parity records (when using a pedigree analysis), and this potentially suggests that causes of lameness in later lactations are influenced more by environmental (e.g., management) factors and less by genetics; further analysis to confirm this is required. Whereas lameness had estimates of 0 heritability for the genomic analysis for first and all parity, this may be associated with the fact that causes of lameness (e.g., infection and trauma) were combined. However, the incidences of specific types of lameness were very low, making genetic parameter estimation for them difficult.

Even though heritability estimates are low for health traits, we found enough genetic variation (higher coefficient of genetic variation reported) to make genetic gains in these traits. The advantage with the coefficient of genetic variation compared with heritability, is that it scales the measure of additive genetic variance by the trait mean instead of by the total variance, so it is not confounded by the magnitude of the environmental variance (Burdon, 2008). Also, repeatability of health traits were only slightly higher than the heritabilities for most traits, indicating that genetics is the predominate source of cow variance.

The high positive genetic correlations between diseases suggest that disease traits are controlled by similar genes and selection on one would bring about a genetic change in the other. The high genetic correlations between the all diseases and individual disease traits opens up the potential for selecting for overall disease resistance. The advantage of capturing diseases in a single trait includes minimizing the effects of diagnostic or recording errors done by farmers, and data editing and analysis would be simplified (Hansen et al., 2002; Haile-Mariam and Goddard, 2010).

Genetic correlation estimates between production and health traits suggest that, to minimize any increase in incidence of health problems associated with selection for production traits and address animal welfare issues, selection for health traits should be part of the dairy cattle selection program. This is important because the incidence of health problems, particularly those associated with intensity of production, will likely increase with the increase in productivity of dairy cattle. Most of the relationships between the diseases and other traits of interest to the dairy farmer [BCS, fertility, SCC, production traits (milk, fat, and protein yields), survival, angularity, and udder and body depth] are in agreement with other studies (Pryce et al., 1997; Zwald et al., 2004b; Haile-Mariam and Goddard, 2010; Koeck et al., 2012a), and are also similar to the relationships to fertility (Pryce et al., 1997; Haile-Mariam et al., 2004).

Selection for improvements in health traits is optimal when included in a multitrait selection index. Further research would be needed to quantify the responses to selection of the traits in the Australian economic index, called the Balanced Performance Index. This would require working out the economic values for health traits and their contribution to the overall breeding objective, to recognize potential value in having individual health breeding values, or having a broad-based all-disease resistance breeding value. Health traits have been indirectly selected for over the past few years in the dairy industry, such as for mastitis resistance by selecting for SCC (genetically correlated with mastitis) and survival (longevity). However, mastitis still remains a major problem in the dairy industry, as it still occurs at comparatively high frequencies, costs are high (Schroeder, 2012), and there is concern for animal welfare. Such factors validate the importance of having direct health 
breeding values in the future to reduce production costs and, most importantly, improve animal welfare.

Direct selection for improved disease resistance based on recorded veterinary treatments has been carried out for more than 30 yr in Scandinavian countries (Heringstad et al., 2003; Østerås et al., 2007; Heringstad and Osteras, 2013). In Norway, there have been reductions of $30 \%$ in clinical mastitis cases as a result of genetic improvement (Heringstad et al., 2003, 2007). Overall treatment rates have also reduced due to the associated capturing of health data, which played a huge role in developing management and breeding tools for genetic improvement of health traits in Norwegian dairy cows (Heringstad et al., 2003). Hence, potential exists to make similar genetic progress in health traits in the Australian dairy industry; this highlights the importance of continued health data capture.

The reliabilities of genomic breeding values are only as good as the data used. The results from our study are in line with expectations for a small data set and have provided the foundations for future research in the area of dairy health. For the Jersey breed, more data are needed to evaluate and provide reliable estimates. Our study demonstrates the value of having cows genotyped and added to the reference population. The reliabilities were higher and looked more promising when bulls had daughters in the reference population, but not when they only had genomic information. Challenges and limitations exist to the cross-validation method used for our study, more so when working with binary traits and low frequency of records (such as for metabolic diseases and reproductive disorders). Given the size of the validation data set used to assess the reliability of genomic predictions (494 bulls with an average of 14 daughters per sire), can result in many sires having 0 disease among daughters, leading to the very low reliabilities estimated. Therefore, collection of more data and having larger daughter groups will allow us to have more reliable sets of bulls for validations in the near future. For traits such as metabolic diseases, the use of measures that are indicative of subclinical disease (such as measurements of BHB) can better objectively define ketosis, for example.

Promising reliabilities were achieved for mastitis, and further potential exists to improve the reliability of mastitis breeding values by using combinations of predictor traits, such as the inclusion of both mastitis and SCC data to better improve the prediction of mastitis (Mrode and Swanson, 1996; Green et al., 2004; de Haas et al., 2008; Urioste et al., 2010; Windig et al., 2010; Koeck et al., 2012b). The value of having direct health trait breeding values and predictor traits opens up the potential for faster and greater responses to selection.
For traits with very low heritability estimates, such as lameness, there may be merit in recording types of lameness (laminitis and so on; Buch et al., 2011; Häggman and Juga, 2013). Routine hoof trimming is not a common management practice in Australia, unlike in European and North American countries, so we need to look for other opportunities such as developing new recording protocols. Collation of more data and training to assist differentiation between types of lameness may help to develop genomic breeding values for this trait. In Europe and America, success has been achieved in herds recording types of lameness (Malchiodi et al., 2015). For traits with low heritability, such as health traits, we see the benefits of having a dedicated reference population of genotyped cows in terms of the improvements in reliabilities that can be achieved (Plieschke et al., 2016). Improving reliability is a key to the success of genomic selection. Once high accuracy of selection is achievable for health traits, fast genetic gains are then possible (Berry, 2015).

\section{CONCLUSIONS}

This study has provided an insight into what health data are actually being collected on farm, showing that a source of health data is available that can be accessed and potentially used for the genetic improvement of health traits in Australian herds. Mastitis is the most commonly occurring disease in dairy herds, followed by reproductive disorders. Lameness and metabolic problems occur at lower incidence. Preliminary investigations have indicated a possible issue of underrecording of disease events, where we suspect only the most severe cases (clinical) were being recorded. From a breeding context, this would mean that selection can then be against severe cases of disease. Heritability of health traits were generally low, yet the industry has been able to make genetic improvements with low heritable traits such as fertility traits (4\%). Value exists in directly selecting for such traits, and this study has demonstrated the possibility of making genetic progress toward profitable, healthy cows. The advantage of having a genotyped population is that it opens up new opportunities for genomic selection of dairy health traits and the collection of new phenotypes for the development of new traits. We also see the value of having a dedicated reference population of genotyped cows in the improvement that can be achieved in reliabilities of new and existing genomic breeding values.

\section{ACKNOWLEDGMENTS}

The research for the health data for healthy cows project was funded by the Gardiner Dairy Research 
Foundation (Melbourne, Australia), managed through Dairy Australia (Melbourne) and research undertaken by Holstein Australia (Hawthorn, Victoria, Australia) and Victorian Government (DEDJTR) researchers (Bundoora, Victoria, Australia). Cow genotypes were obtained from the Dairy Futures CRC (Bundoora, Victoria, Australia) Ginfo project and we thank DataGene (Bundoora, Victoria, Australia) for supplying the phenotypes and genotypes used in this study. We also greatly thank the Ginfo farmers for their participation in allowing us to access their on-farm health data and their respective herd test centers for supplying the health data files.

\section{REFERENCES}

Berry, D. P. 2015. Breeding the dairy cow of the future: What do we need? Anim. Prod. Sci. 55:823-837.

Buch, L. H., A. C. Sørensen, J. Lassen, P. Berg, J. A. Eriksson, J. H. Jakobsen, and M. K. Sørensen. 2011. Hygiene-related and feedrelated hoof diseases show different patterns of genetic correlations to clinical mastitis and female fertility. J. Dairy Sci. 94:1540-1551.

Burdon, R. D. 2008. Short note: Coefficients of variation in variables with bounded scales. Silvae Genet. 57:179.

Byrne, T. J., B. Santos, P. Amer, D. Martin-Collado, J. E. Pryce, and M. Axford. 2016. New breeding objectives and selection indices for the Australian dairy industry. J. Dairy Sci. 99:8146-8167.

Chesnais, J. P., T. A. Cooper, G. R. Wiggans, M. Sargolzaei, J. E. Pryce, and F. Miglior. 2016. Using genomics to enhance selection of novel traits in North American dairy cattle. J. Dairy Sci. 99:2413-2427.

Clarkson, M. J., D. Y. Downham, W. B. Faull, J. W. Hughes, F. J. Manson, J. B. Merritt, R. D. Murray, W. B. Russell, J. E. Sutherst, and W. R. Ward. 1996. Incidence and prevalence of lameness in dairy cattle. Vet. Rec. 138:563-567.

de Haas, Y., W. Ouweltjes, J. ten Napel, J. J. Windig, and G. de Jong. 2008. Alternative somatic cell count traits as mastitis indicators for genetic selection. J. Dairy Sci. 91:2501-2511.

Dechow, C. D., G. W. Rogers, U. Sander-Nielsen, L. Klei, T. J. Lawlor, J. S. Clay, A. E. Freeman, G. Abdel-Azim, A. Kuck, and S. Schnell. 2004. Correlations among body condition scores from various sources, dairy form, and cow health from the United States and Denmark. J. Dairy Sci. 87:3526-3533.

Dohoo, I. R., and S. W. Martin. 1984. Disease, production and culling in Holstein-Friesian cows III. Disease and production as determinants of disease. Prev. Vet. Med. 2:671-690.

Egger-Danner, C., J. B. Cole, J. E. Pryce, N. Gengler, B. Heringstad, A. Bradley, and K. F. Stock. 2015. Invited review: Overview of new traits and phenotyping strategies in dairy cattle with a focus on functional traits. Animal 9:191-207.

Erb, H. N., R. D. Smith, R. B. Hillman, P. A. Powers, M. C. Smith M. E. White, and E. G. Pearson. 1984. Rates of diagnosis of six diseases of Holstein cows during 15-day and 21-day intervals. Am. J. Vet. Res. 45:333-335.

Espejo, L. A., M. I. Endres, and J. A. Salfer. 2006. Prevalence of lameness in high-producing Holstein cows housed in freestall barns in Minnesota. J. Dairy Sci. 89:3052-3058.

Gianola, D. 1982. Theory and analysis of threshold characters. J. Anim. Sci. 54:1079-1096.

Gilmour, A. R., B. J. Gogel, B. R. Cullis, S. J. Welham, and R. Thompson. 2015. ASReml User Guide Release 4.1 Structural Specification, VSN International Ltd., Hemel Hempstead, UK. www .vsni.co.uk

Green, M. J., L. E. Green, Y. H. Schukken, A. J. Bradley, E. J. Peeler, H. W. Barkema, Y. de Haas, V. J. Collis, and G. F. Medley. 2004.
Somatic cell count distributions during lactation predict clinical mastitis. J. Dairy Sci. 87:1256-1264.

Häggman, J., and J. Juga. 2013. Genetic parameters for hoof disorders and feet and leg conformation traits in Finnish Holstein cows. J. Dairy Sci. 96:3319-3325

Haile-Mariam, M., P. J. Bowman, and M. E. Goddard. 2004. Genetic parameters of fertility traits and their correlation with production, type, workability, liveweight, survival index and cell count. Aust. J. Agric. Res. 55:77-87.

Haile-Mariam, M., and M. E. Goddard. 2010. Preliminary genetic analyses of voluntarily supplied disease data in Australian dairy herds. Anim. Prod. Sci. 50:186-192.

Haile-Mariam, M., G. J. Nieuwhof, K. T. Beard, K. V. Konstatinov, and B. J. Hayes. 2013. Comparison of heritabilities of dairy traits in Australian Holstein-Friesian cattle from genomic and pedigree data and implications for genomic evaluations. J. Anim. Breed. Genet. 130:20-31

Haile-Mariam, M., E. Schelfhors, and M. E. Goddard. 2007. Effect of data collection methods on the availability of calving ease, fertility and herd health data for evaluating Australian dairy cattle. Aust. J. Exp. Agric. 47:664-671.

Hansen, M., M. S. Lund, M. K. Sørensen, and L. G. Christensen 2002. Genetic parameters of dairy character, protein yield, clinical mastitis, and other diseases in the Danish Holstein cattle. J. Dairy Sci. 85:445-452.

Heringstad, B., G. Klemetsdal, and T. Steine. 2007. Selection responses for disease resistance in two selection experiments with Norwegian Red cows. J. Dairy Sci. 90:2419-2426.

Heringstad, B., and O. Osteras. 2013. More than 30 years of health recording in Norway. ICAR 2013 Health Data Conference: Challenges and Benefits of Health Data Recording in the Context of Food Chain Quality, Management and Breeding. 30-31 May 2013, Århus, Denmark. International Committee for Animal Recording (ICAR), Rome, Italy.

Heringstad, B., R. Rekaya, D. Gianola, G. Klemetsdal, and K. A. Weigel. 2003. Genetic change for clinical mastitis in Norwegian Cattle: a threshold model analysis. J. Dairy Sci. 86:369-375.

Hogeveen, H., K. Huijps, and T. J. G. M. Lam. 2011. Economic aspects of mastitis: New developments. N. Z. Vet. J. 59:16-23.

Jamrozik, J., J. Fatehi, G. J. Kistemaker, and L. R. Schaeffer. 2005. Estimates of genetic parameters for Canadian Holstein female reproduction traits. J. Dairy Sci. 88:2199-2208.

Kadarmideen, H. N., and J. E. Pryce. 2001. Genetic and economic relationships between somatic cell count and clinical mastitis and their use in selection for mastitis resistance in dairy cattle. Anim. Sci. $73: 19-28$.

Kadarmideen, H. N., R. Thompson, and G. Simm. 2000. Linear and threshold model genetic parameters for disease, fertility and milk production in dairy cattle. Anim. Sci. 71:411-419.

Koeck, A., F. Miglior, D. F. Kelton, and F. S. Schenkel. 2012a. Health recording in Canadian Holsteins: Data and genetic parameters. J. Dairy Sci. 95:4099-4108.

Koeck, A., F. Miglior, D. F. Kelton, and F. S. Schenkel. 2012b. Alternative somatic cell count traits to improve mastitis resistance in Canadian Holsteins. J. Dairy Sci. 95:432-439.

Loker, S., F. Miglior, A. Koeck, T. F.-O. Neuenschwander, C. Bastin, J. Jamrozik, L. R. Schaeffer, and D. F. Kelton. 2012. Relationship between body condition score and health traits in first-lactation Canadian Holsteins. J. Dairy Sci. 95:6770-6780.

Malchiodi, F., A. Christen, and F. Miglior. 2015. Can breeding improve hoof health? Dairy Global. 2:11-13. http://dairyhoofhealth .info/DG2_11.pdf.

Miglior, F., A. Koeck, D. F. Kelton, F. S. Schenkel, C. Egger-Danner, O. K. Hansen, K. Stock, J. E. Pryce, J. Cole, N. Gengler, and Associates. 2013. Comparison of different methods to validate a dataset with producer-recorded health events. Pages 109-116 in Challenges and Benefits of Health Data Recording in the Context of Food Chain Quality, Management and Breeding. Proceedings of the ICAR Conference, Aarhus, Denmark, May 30-31, 2013. International Committee for Animal Recording (ICAR), Rome, Italy. 
Miglior, F., B. L. Muir, and B. J. Van Doormaal. 2005. Selection indices in Holstein cattle of various countries. J. Dairy Sci. 88:12551263.

Moreno, C., D. Sorensen, L. A. Garcia-Cortés, L. Varona, and J. Altarriba. 1997. On biased inferences about variance components in the binary threshold model. Genet. Sel. Evol. 29:145-160.

Mrode, R. A., and G. J. T. Swanson. 1996. Genetic and statistical properties of somatic cell count and its suitability as an indirect means of reducing the incidence of mastitis in dairy cattle. Anim. Breed. Abstr. 64:847-856.

Negussie, E., I. Strandén, and E. A. Mäntysaarl. 2008. Genetic analysis of liability to clinical mastitis, with somatic cell score and production traits using bivariate threshold-linear and linear-linear models. Livest. Sci. 117:52-59.

Neuenschwander, T. F.-O. 2010. Studies on disease resistance based on producer-recorded data in Canadian Holsteins. PhD Thesis. University of Guelph, Guelph, ON, Canada.

Neuenschwander, T. F.-O., F. Miglior, J. Jamrozik, O. Berke, D. F. Kelton, and L. R. Schaeffer. 2012. Genetic parameters for producer-recorded health data in Canadian Holstein cattle. Animal $6: 571-578$.

Østerås, O., H. Solbu, A. O. Refsdal, T. Roalkvam, O. Filseth, and A. Minsaas. 2007. Results and evaluation of thirty years of health recordings in the Norwegian dairy cattle population. J. Dairy Sci. 90:4483-4497.

Parker Gaddis, K. L., J. B. Cole, J. S. Clay, and C. Maltecca. 2012. Incidence validation and relationship analysis of producer-recorded health event data from on farm computer systems in the USA. J. Dairy Sci. 95:5422-5435.

Parker Gaddis, K. L., J. B. Cole, J. S. Clay, and C. Maltecca. 2014. Genomic selection for producer-recorded health event data in US dairy cattle. J. Dairy Sci. 97:3190-3199.

Philipsson, J., and B. Lindhé. 2003. Experiences of including reproduction and health traits in Scandinavian dairy cattle breeding programmes. Livest. Prod. Sci. 83:99-112.

Plieschke, L., C. Edel, C. G. E. Pimentel, R. Emmerling, J. Bennewitz, and K. U. Götz. 2016. Systematic genotyping of groups of cows to improve genomic estimated breeding values of selection candidates. Genet. Sel. Evol. 48:73.

Pryce, J. E., M. Haile-Mariam, P. Bowman, T. Nguyen, K. Konstantinov, G. J. Nieuwhof, and B. J. Hayes. 2013. Improving the reliability of fertility breeding values in Australian dairy cattle. Proc.
Assoc. Adv. Anim. Breed. Genet. 20:33-36. Association for the Advancement of Animal Breeding and Genetics, Napier, New Zealand.

Pryce, J. E., R. F. Veerkamp, R. Thompson, W. G. Hill, and G. Simm. 1997. Genetic aspects of common health disorders and measures of fertility in Holstein Friesian dairy cattle. Anim. Sci. 65:353-360.

Ramirez-Valverde, R., I. Misztal, and J. K. Bertrand. 2001. Comparison of threshold vs. linear and animal vs sire models for predicting direct and maternal genetic effects on calving difficulty in beef cattle. J. Anim. Sci. 79:333-338.

Rauw, W. M., and L. Gomez-Raya. 2015. Genotype by environment interaction and breeding for robustness in livestock. Front. Genet. $6: 310$.

Rauw, W. M., E. Kanis, E. N. Noordhuizen-Stassen, and F. J. Grommers. 1998. Undesirable side effects of selection for high production efficiency in farm animals: A review. Livest. Prod. Sci. 56:15-33.

Sander-Nielsen, U., G. A. Pedersen, J. Pedersen, and P. Sørensen. 1999. Genetic variation in disease traits and their relationships with survival in Danish dairy cattle. Interbull Bull. 21:170-177.

Schroeder, J. 2012. Mastitis control programs. North Dakota State University Extension Service, Fargo. https://www.ag.ndsu.edu/ pubs/ansci/dairy/as1129.pdf.

Stevenson, M. A. 2000. Disease incidence in dairy herds in the southern highlands district of NSW Australia. Prev. Vet. Med. 43:1-11.

Urioste, J. I., J. Franzén, and E. Strandberg. 2010. Phenotypic and genetic characterization of novel somatic cell count traits from weekly or monthly observations. J. Dairy Sci. 93:5930-5941.

Windig, J. J., W. Ouweltjes, J. ten Napel, G. de Jong, R. F. Veerkamp, and Y. de Haas. 2010. Combining somatic cell count traits for optimal selection against mastitis. J. Dairy Sci. 93:1690-1701.

Yang, J., B. Benyamin, B. McEvoy, S. Gordon, A. Henders, D. Nyholt, P. Madden, A. Heath, N. Martin, G. Montgomery, M. E. Goddard, and P. M. Visscher. 2010. Common SNPs explain a large proportion of the heritability for human height. Nat. Genet. 42:565-569.

Zwald, N. R., K. A. Weigel, Y. M. Chang, R. D. Welper, and J. S. Clay. 2004a. Genetic selection for health traits using producer recorded data. I. Incidence rates, heritability estimates, and sire breeding values. J. Dairy Sci. 87:4287-4294

Zwald, N. R., K. A. Weigel, Y. M. Chang, R. D. Welper, and J. S. Clay. 2004b. Genetic selection for health traits using producer recorded data. II. Genetic correlations, disease probabilities, and relationships with existing traits. J. Dairy Sci. 87:4295-4302. 